\title{
O contexto na crítica literária de Antonio Candido e Pier Paolo Pasolini: Elementos para uma comparação
}

\author{
The context in literary critics of Antonio Candido \\ and Pier Paolo Pasolini: Elements for a comparison
}

\section{Gesualdo MafFia*}

Resumo: comparação entre às análises críticas de Antonio Candido e Pier Paolo Pasolini, focada, respectivamente, nos ensaios O Mundo Provérbio e Intervenção Sobre O Discurso Indirecto Livre. O objetivo é evidenciar algumas diferenças entre a crítica acadêmica e a crítica militante dos dois autores.

Abstract: Comparison between Antonio Candido's and Pier Paolo Pasolini's critical analyses, focused, on the essays $O$ Mundo Provérbio and Intervenção Sobre O Discurso Indirecto Livre. The aim is to underline on the differences between the academic and the militant criticism of both authors.

Palavras-chave: Antonio Candido, Pier Paolo Pasolini, Estilo Indireto Livre, Crítica Acadêmica, Crítica Militante.

Keywords: Antonio Candido, Pier Paolo Pasolini, Free Indirect Speech, Academic Criticism, Militant Criticism.

\footnotetext{
* Doutor em História Contemporânea pela Universidade de Génova (Itália), doutorando em Letras Modernas pela FFLCH-USP.
} 
No ensaio O Mundo Provérbio, publicado pela primeira vez em 1972, Antonio Candido desenvolve uma análise estrutural do livro I Malavoglia de Giovanni Verga, chamando a atenção, entre outras questões, para o uso do estilo indireto livre, estilo narrativo muito usado pelos escritores europeus do século XIX. O objetivo do crítico nesse ensaio é "analisar a convergência do elemento linguístico e do elemento social, no encontro de uma solução admiravelmente adequada para sugerir o mundo fechado" do romance (CANDIDO, 2004, p. 92). Nestas páginas, pretendo esboçar uma reflexão sobre as diferentes visões de Antonio Candido e Pier Paolo Pasolini para esse tipo de 'convergência' linguística e social, analisando e comparando $O$ Mundo Provérbio e o artigo de Pasolini Intervento Sul Discorso Libero Indiretto (Intervenção Sobre O Discurso Indirecto Livre), publicado pela primeira vez em $1965 .^{1}$

Começamos com o ensaio do crítico brasileiro.

O mundo fechado ao qual se refere Candido é aquele de uma pequena aldeia da Sicília da segunda metade do século XIX; uma realidade que parece fora do tempo, na qual a Grande História aparece como fonte de problemas e até de tragédias familiares (como a morte de Luca na 3ạ Guerra de Independência Italiana de 1866). Portanto, o tempo não é histórico, mas sim geográfico: caracterizado pela circularidade das estações e dos trabalhos camponeses. $O$ tempo cíclico se reflete na "estrutura circular [do romance] que se manifesta em vários níveis, indicando a recorrência dos problemas e das soluções, como se cada geração recomeçasse no mesmo ponto, com o imobilismo das organizações sociais estagnadas" (CANDIDO, 2004, p. 81). Com a reconstrução de um mundo marginal, atrasado, de vencidos ("I vinti" - como Verga chama o ciclo inacabado de obras que começa com o romance I Malavoglia), Verga conseguiu realizar uma das obras literárias mais importantes de sua época na Itália. Nesse sentido, a pesquisa e a escolha de uma linguagem adequada ao cenário regionalista foi o elemento decisivo para a realização desse romance. O paralelo Zola-Verga possibilita, na análise de Antonio Candido, a individuação de elementos comuns entre os dois autores, focando a atenção no tipo de língua literária utilizada e no modo de usar o estilo indireto livre.

\footnotetext{
${ }^{1}$ Não existe tradução no Brasil, mas foi publicado em Lisboa, pela Assírio e Alvim em 1982, com o título Empirismo herege. O ensaio saiu pela primeira vez na revista Paragone, dirigida por Roberto Longhi, Prof. de História da Arte nas Universidades de Bolonha e Florença.
} 
No que se refere à língua literária, o crítico sublinha as dificuldades enfrentadas por Verga na escolha e na criação dessa língua no contexto linguístico e cultural italiano. Com efeito, enquanto Zola "dispunha de um idioma longamente trabalhado na tradição da sua literatura por experiências de simplificação, que lhe deram bem cedo certo tipo de artificialidade natural", Verga "tinha pela frente a língua literária italiana”, altamente seletiva, retórica, pomposa, baseada na "proscrição do coloquial e da simplicidade, consideradas dimensões não-literárias" (CANDIDO, 2004, p. 90).

Naquele momento, o romance estava tentando se afirmar no ambiente literário italiano, no qual era considerado um gênero secundário em relação àqueles "nobres" da tradição culta. Apenas com Os Noivos, de Alessandro Manzoni, o romance começou a se caracterizar pelo conteúdo cotidiano e popular, "podando a galharia de epopéia e oratória, de ode e tragédia que tinha sido o seu universo predileto" (Ibidem). Sobre este assunto, Pasolini afirma que, ao final do século $\mathrm{XIX}$, os críticos e os filólogos italianos estavam atrasados na procura de uma patente de italianidade para os gêneros tradicionais, e a vida intelectual do País era um mero reflexo daquela francesa na tentativa de entrar em contato com o povo. A falta de uma revolução com consequências sociais, culturais e antropológicas parecidas com aquelas da Revolução de 1789, suscita nos intelectuais italianos certa artificialidade, que continua nas décadas seguintes:

(...) la letteratura italiana è una letteratura d'élites intellettuali, la cui storia stilistica è una storia d'individui protetti, nell'inventio, da una koinè già "per letteratura", da una parte, e dall'altra da una condizione sociale preservante l'io nella sua passione estetica a coltivare o le abnormità di tipo religioso o intimistico o l'otium classicheggiante e squisito (PASOLINI, 2009, p. 298). ${ }^{2}$

Portanto, se o narrador de Zola, em L'Assommoir, possuía "duas possibilidades dentro da mesma língua (linguagem do homem culto e linguagem do operário inculto)" para se expressar, o de Verga, em I Malavoglia, tinha diante de si (e nisso consiste sua maior dificuldade) quatro opções linguísticas, devido à caracte-

\footnotetext{
2 "A literatura italiana é uma literatura de elites intelectuais, cuja história estilística é uma história de indivíduos protegidos, na inventio, de um lado por uma koiné já concebida 'para a literatura'; de outro, por uma condição social que mantém o eu na sua paixão estética para cultivar as anormalidades de tipo religioso ou intimistas ou o otium clássico e refinado". Tradução minha.
} 
rística específica do regionalismo de ambientação siciliana, o chamado Verismo italiano: "toscano culto, toscano popular; siciliano eventualmente submetido a tratamento literário, siciliano popular" (CANDIDO, 2004, p. 91). Verga inventou um estilo narrativo que predominou por 50 anos na Itália e que permitiu, de certa forma, resolver dois problemas: "guardar a autenticidade da marca regional e ao mesmo tempo ser entendido pelos leitores cultos" e "dar o cunho da língua da Sićlia e integrar o livro no universo da literatura nacional". A tensão está entre a exigência de expressividade e de comunicação, na procura de uma linguagem, rica em elementos coloquiais, gírias locais, provérbios "filtrados pelo desejo de aparentar espontaneidade" (Ibid., p. 90).

Passamos a nos deter agora na segunda questão, o uso do estilo indireto livre. Sabemos que esta estrutura narrativa mistura enunciados do narrador aos dos personagens, combinando as características dos discursos direto e indireto. Conserva a afetividade e a expressividade típicas do discurso direto, e mantém a transposição de pronomes, verbos e advérbios próprios do discurso indireto. Traduz o mundo interior do personagem, dando a sensação que o narrador penetra em seus pensamentos e os revela ao leitor. $\mathrm{O}$ uso deste estilo representa uma revolução nos romances daquela época. Para Antonio Candido, com L'Assommoir, Zola foi provavelmente o artífice dessa revolução. Verga de certa forma a continua em I Malavoglia, gerando uma voz narrativa que "aproxima o narrador do personagem, graças à intimidade facultada por uma espécie de extensão do estilo indireto livre, cujas virtudes, na prática literária, aparecem geralmente intercaladas entre as outras modalidades, mas aqui são por assim dizer permanentes" (Ibid., p. 93). O resultado, mesmo permanecendo dentro "do artifício linguístico adotado conscientemente" pelo autor, é uma homogeneidade entre ele e os personagens. Esta homogeneidade, efetuada por um narrador que parece totalmente integrado na cultura do povo siciliano, suscita "um poderoso senso de realidade".

Além disso, para Antonio Candido, a escolha do estilo indireto livre em Verga precisa de uma definição mais específica. Portanto, o crítico prefere falar em "estilo indireto homogeneizador (...) para designar a tonalidade obtida pela generalização das virtudes mediadoras do indireto livre". A inovadora convergência entre elemento linguístico e elemento social se realiza aqui:

Refletindo sobre o estilo de I Malavoglia ou de certos contos excepcionalmente 
bem realizados, como Rosso Malpello [sic], não se pode deixar de sentir o que há de fundamentalmente revolucionário nessa supressão de barreiras, nessa aproximação rumo ao povo através do ritmo profundo de sua vida, traduzido na fala. A invenção estilística funciona como nivelamento social, de tal modo que, mesmo sem qualquer alusão política, e mesmo sem tensão clara de sugeri-la, o romancista efetua uma espécie de vasta igualitarização ( $/$ bid.).

Antonio Candido individua também os traços que "amarram" a narrativa à linguagem (o lugar-comum, a repetição e o provérbio), usados para a reconstrução do mundo siciliano fechado e recorrente. Não precisamos aprofundar agora esses aspectos, porque já temos alguns elementos interessantes para uma comparação com as reflexões de Pasolini.

Em Intervento Sul Discorso Indiretto Libero, uma resenha que possui a densidade de um ensaio teórico ${ }^{3}$, Pasolini declara a própria insatisfação por uma crítica acadêmica em que dificilmente se podem encontrar "as razões efectivas de um emprego gramatical e de um processo estilístico que implicam uma tão grande massa de intenções, conscientes e inconscientes" (PASOLINI, 1982, p. 63). Podemos ver, assim, como ele enfrenta a questão da convergência entre elementos linguísticos e sociais: ou seja, atua do ponto de vista de um crítico militante. Diferentemente do ensaio de Antonio Candido, em Pasolini encontramos considerações sobre várias obras e vários autores. O verdadeiro enfoque de sua análise é o estilo indireto livre, mas como categoria que se expande para além das suas funções estilísticas e gramaticais.

No início, Pasolini se concentra sobre o uso dos tempos verbais: infinitivo, pretérito perfeito ('passato remoto') ${ }^{4}$, imperfeito. Ele usa como exemplo alguns versos do libretista Lorenzo Da Ponte ${ }^{5}$ sobre a vida dura dos seres humildes. $\mathrm{O}$ infinitivo usado no estilo indireto livre tem uma função épica e "incoativa", ou seja, de descrição de ações repetidas. Nele existe uma normatividade especial,

\footnotetext{
${ }^{3} \mathrm{O}$ livro resenhado, uma das maiores contribuções críticas para a área, é HERCZEG, Giulio. Lo stile indiretto libero in italiano. Florença: Sansoni, 1963.

${ }^{4}$ Em italiano, o passato remoto, equivalente ao pretérito perfeito em português, é hoje em dia um tempo literário, enquanto o passado mais usado na fala e na escrita é um tempo composto, o passato prossimo.

${ }^{5}$ Ibid. Noite e dia aguentar/por que não sabe entender;/chuva o vento suportar/dormir mal e mal comer./Quero fazer-me fidalgo/e não ter que obedecer. Lorenzo Da Ponte (1749-1838) foi um célebre libretista de ópera.
} 
devido ao "coro" dos destinatários das mensagens, que compartilham regras e normas próprias de uma categoria social. Esta experiência popular se institucionaliza, porque é "típica de toda a normatividade dos provérbios ou dos cantores dos ofícios" e "pode atingir certa forma de épica". O elemento "incoativo" reforça esta normatividade, suscitando "sentimentos de empatia em outras pessoas, que não só fizeram experiências semelhantes, mas que não têm sequer a possibilidade de pensar, por si sós experiências diversas" (Ibid., p. 64). O uso do infinitivo no estilo indireto livre representa, portanto, a simpatia do autor não apenas pelo locutor, mas por todos que vivem e participam de seu mundo.

O que mais atrai Pasolini no estilo indireto livre é a forma que esse estilo adquire quando o escritor-narrador "mergulha imediatamente na sua personagem, narrando tudo através desta" (Ibid., p. 65). Em um livro que utilize somente o estilo indireto livre, o narrador indireto, escolhido pelo autor entre os personagens, usa inevitavelmente o pretérito perfeito. Essa operação de técnica literária tem dois objetivos ou motivos diferentes: 1 . Tornar ficticiamente objetivo o que o autor pretende dizer por meio do personagem; 2. Procurar uma verdadeira objetividade na narração de um mundo socialmente diferente daquele do autor.

O segundo desses objetivos é empregado por Pasolini nos seus romances dos anos de 1950 (especialmente em Una Vita Violenta), mas também se encontra em I Malavoglia de Verga. Pasolini aprecia o resultado do romance de Verga, pelo caráter épico definitivo alcançado, que transmite outra experiência vital, ou seja, de uma classe social diferente. No trecho abaixo, vemos que Pasolini começa a mudar o modo de enfrentar o assunto, aceitando a "invasão" do contexto externo à obra em sua atividade crítica:

Todos os pretéritos perfeitos de Verga são "épicos": são tempos de um discurso revivido colectivamente em todas as suas personagens: e a "condição estilística" deste discurso dilata-se até incluir o livro inteiro. Essa operação surgia em Verga como uma ilusão naturalista ainda não separada das regressões românticas dos sujeitos falantes, do mito romântico do povo: mas era claro existir alguma coisa que presidia a estas duas operações românticas participantes da ideologia literária, das correntes do pensamento estético. Direi, pouco originalmente, que se tratava (sem que Verga o soubesse) da presença da visão da história em termos de luta de classes de Marx (lbid.). 
A partir de então, Pasolini não consegue - e não quer - manter o foco nas obras. Além disso, ele precisa mudar a concepção do estilo indireto livre. As funções retórica e gramatical se tornam secundárias em relação à presença, explícita ou não, de uma "consciência sociológica" por parte do autor, que representa, para Pasolini, "a característica mais fundamental e constante" deste estilo (Ibid., p. 66). Separando a condição estilística da gramatical, Pasolini consegue ler autores clássicos da história literária italiana, considerando-os antecedentes significativos no uso do estilo indireto livre. Ludovico Ariosto e até mesmo Dante Alighieri, sem usar explicitamente ou significativamente este estilo, vivem em suas obras a consciência da própria condição social. Nos dois autores, a relação revolucionária entre língua "alta" - o latim da cultura teológica - e língua "baixa" - falada pela burguesia das cidades toscanas da Idade Média e do Renascimento - oferece o primeiro sintoma de uma consciência social. Em Dante, esta consciência é mais acentuada, distinta pelas falas dos vários grupos sociais, o que dá a sensação de uma visão "profundamente democrática, dada a sua ascendência provável de experiências colhidas na vida das corporações e nas lutas sociais que se lhes ligavam" (Ibid., p. 68). Ariosto aproxima a língua da poesia e da prosa por meio da ironia e "reconduz ao seu próprio nível de burguês irónico e céptico (...) a língua da cavalaria idealizada na língua da poesia (...); inicia a longa obra de erosão do humanismo, que, nos nossos dias, acabará por degenerar de pragmatismo em qualunquismo". ${ }^{6}$

Pasolini volta a enfrentar, como havia feito em outros ensaios daquela época, o problema da falta de uma língua nacional e de uma verdadeira cultura italiana. Para ele, não existe ainda, nos anos de 1960, uma análise adequada do estilo indireto livre em italiano, porque se considera "como axiomática a existência de um nível médio e normal do italiano (falado ou literário)" (Ibid., p. 68). Coisa falsa, porque os escritores que pescam nas zonas baixas da língua são os mesmos que geralmente trabalham com suas formas mais refinadas. $O$ que essa falta de consciência representa para a literatura contemporânea é muito grave para $\mathrm{Pa}$ solini. Ele chega até mesmo a atacar os escritores burgueses, que só conseguem criar personagens que compartilham de sua ideologia:

\footnotetext{
${ }^{6}$ Ibid., p. 66. Qualunquismo é um termo do léxico político italiano, baseado num movimento político nascido depois da Segunda Guerra Mundial, que se poderia traduzir em português como indiferentismo. Cfr. (LAHUD, 1993, p. 133), (BUAES, 2009).
} 
O que há de mais odioso e de mais intolerável, mesmo no mais inocente dos burgueses, é não saber reconhecer outras experiências vitais que não sejam a sua: e reconduzir todas as demais expêriencias vitais a uma analogia substancial relativa à sua própria experiência (...). Um escritor burguês, ainda que nobre, ainda que grande, mas que não saiba reconhecer o carácter extremo da diferença psicológica de um homem com experiências vividas diferentes das suas (...) realiza um acto que é o primeiro passo em direcção a formas de defesa de privilégios, ou mesmo de racismo: neste sentido, também o autor não é livre, mas pertence deterministicamente à sua classe: não há solução de continuidade entre ele próprio e um comissário da polícia ou um carrasco de um campo de extermínio (Ibid., p. 70).

A expansão da concepção do estilo indireto livre continua e entra diretamente na polêmica contra as neovanguardas italianas e sua atitude apocalíptica contra a língua da tradição em busca da língua do futuro. Sem abordar esse assunto, temos elementos suficientes para traçar as diferenças entre os dois ensaios discutidos sumariamente nestas páginas.

No Prefácio de $O$ Discurso E A Cidade, Antonio Candido explica as razões da escolha dos ensaios e da organização interna do livro. A primeira parte, que contém O Mundo Provérbio, apresenta estudos sobre romances tributários da concepção realista. O crítico deixa claro, desde o começo, que a sua redução estrutural é uma crítica que integra e mostra "de que maneira a narrativa se constitui a partir de materiais não literários, manipulados a fim de se tornarem aspectos de uma organização estética regida pelas suas próprias leis, não as da natureza, da sociedade ou do ser". O crítico deve ter em consideração o ponto de vista do leitor, a impressão de realidades vitais que as obras suscitam nele. Mas deve manter a ambição de "mostrar como o recado do escritor se constrói a partir do mundo, mas gera um mundo novo, cujas leis fazem sentir melhor a realidade originária", para superar "o valo entre social e estético, ou entre psicológico e estético" (CANDIDO, 2004, p. 9). Portanto, ele não está interessado no estímulo e no condicionamento inicial que provém do contexto exterior (a sociedade, a história, a personalidade), mas no resultado, que é sempre o texto: "a capacidade que os textos possuem de convencer depende muito mais da sua organização própria que da referência ao mundo exterior, pois este só ganha vida na obra literária se for devidamente reordenado pela fatura" (Ibid., p. 10). 
Pasolini, como vimos, tem uma atitude diferente. Ele mantém o foco da análise sobre o autor, o que deixa mais espaço para uma crítica de tipo sociológico e psicológico. A leitura de críticos marxistas - entre eles, Antonio Gramsci e György Lukacs - condicionou muito sua abordagem das obras literárias. Em sua crítica militante, ele tenta destruir, como um furacão, todos os ídolos presentes nas áridas concepções acadêmicas, que se escondem atrás de formas gramaticais, de regras retóricas, da coerência interpretativa. É um escritor que não deixa de usar o contexto político, social (classista!) na sua análise literária, porque quer atacar o exclusivismo da literatura italiana, que considera distante da maioria das pessoas, sejam elas subproletários ou operários, da cidade ou do campo. Por isso, não poupa juízos de tipo moral sobre os autores burgueses.

Sabemos que Antonio Candido, embora não seja só um crítico acadêmico, nunca se definiu marxista e soube distinguir os contextos nos quais desenvolver formas críticas diferentes. Pasolini, por sua vez, nunca deixou de lado a própria militância e sempre tentou manter um diálogo ativo com os partidos e os movimentos esquerdistas, mesmo nas questões literárias. A diferença entre Pasolini e Antonio Candido é que este último mantém o foco de sua análise na experiência literária, enquanto Pasolini deixa que as considerações de cunho literário e político-ideológicos se misturem. A crítica de Pasolini é sempre militante, enquanto Antonio Candido quer e consegue manter uma postura acadêmica.

\section{Referências Bibliográficas}

CANDIDO, Antonio. O discurso e a cidade. São Paulo/Rio de Janeiro: Duas Cidades/Ouro sobre Azul, 2004 (1a. edição 1993).

BUAES, Aline G.. Protegido pelas contradições: Coletânea de Crônicas jornalísticas de Pier Paolo Pasolini (1960-1965). 202 p. Dissertação (Mestrado em Letras) - Universidade de São Paulo. São Paulo, 2009.

LAHUD, Michel. A Vida clara. Linguagens e realidade segundo Pasolini. São Paulo/Campinas: Cia das Letras/Editora Unicamp, 1993.

PASOLINI, Pier Paolo. Empirismo hereje. Lisboa: Assírio e Alvim, 1982, tradução de Miguel Serras Pereira. (Edição original, Empirismo eretico. Milão: Garzanti, 1972).

. Pascoli. In Id., Passione e ideologia. Milão: Garzanti, 2009 (1ª. Ed.

1960). 